\title{
Design and implementation of a multifactor control system for yuba production
}

\author{
Liangyuan XU*, Annan DAI*, Yinjie SHEN*, Yang YANG*, Qing JIANG* and Qiansheng TANG* \\ *School of Engineering, Anhui Agricultural University \\ Changjiang West Road 130, Shushan District, Hefei, Anhui, PR China \\ E-mail: xlyjwh@ahau.edu.cn
}

Received: 8 March 2021; Revised: 8 June 2021; Accepted: 3 August 2021

\begin{abstract}
Currently, the conditions for yuba production are estimated manually. Therefore, this study proposed a multifactor control system using STC12C5A60S2 single-chip machine. For the high-efficiency production of yuba, the optimized production conditions of yuba were obtained through response surface analysis. First, the study designed the hardware and software components of the proposed multifactor control system. Subsequently, the test platform was established to test the effect of the slurry concentration, slurry temperature, slurry PH value, and slurry level. Finally, an orthogonal experiment was performed for response surface analysis, with the yield of yuba being considered as the response value. The results revealed that the control system was determined to exhibit excellent stability and small errors. The optimal yuba production conditions were a slurry concentration, slurry temperature, slurry PH value, and slurry level of $8.50 \%, 85.0{ }^{\circ} \mathrm{C}, 7.0$, and $27.5 \mathrm{~mm}$, respectively, which were associated with a yuba yield of $47.91 \%$.
\end{abstract}

Keywords : Yuba, STC12C5A60S2 MCU, Multifactor control system, Orthogonal experiment, Response surface analysis

\section{Introduction}

Yuba is prepared by refining, filtering, boiling, condensing, and drying soybeans. Several factors, including the slurry temperature, slurry level, slurry concentration, and slurry $\mathrm{pH}$, affect the yield of yuba. Although equipment for continuous yuba production has been developed, the control of production factors has yet to be perfected (Kim et al., 2019; Chen et al., 2010). Current yuba production techniques require considerable manpower, and determining the optimum conditions for yuba production depends on the experience of the producer; therefore, such techniques are characterized by high energy consumption and low efficiency (Kowalczyk et al., 2011; Su et al., 2009; Anchana et al., 2015). Accordingly, designing a multifactor control system and experimentally investigating the optimization of yuba production conditions are critical.

Scholars have proposed several control systems for yuba production. For example, Wenchuan et al. (2016) and Huang (2020) have used the STC12C5A60S2 single-chip microcomputer to design a detector of the total solid content of soy milk and a pH control system, respectively. Furthermore, Jiang et al. (2015) designed a liquid level measurement and control system based on the STC89C51 microcontroller. However, these control systems should be optimized for the multifactor control of yuba production.

Siran et al. (2018) studied the influence of the liquid level and concentration of soy milk on the formation of yuba films. Yongji et al. (2013) investigated the influence of soybean milk concentration, temperature, and heating method on the yield of yuba. Zhi et al. (2005) explored the effects of various soy milk concentrations and slurry depths on yuba production. These studies have focused on one or two factors influencing yuba production. However, research on the optimization of yuba production conditions has yet to be executed.

To resolve the problems pertaining to control systems and to determine optimal yuba production conditions, the present study proposed a novel multifactor control system for yuba production. The hardware and software components of the system were designed and implemented, as detailed herein, and the system was debugged. The response surface analysis was performed to obtain the optimized conditions for yuba production, and a regression model was used for verification of the conditions. 


\section{Overall system design}

The block diagram of the system design is displayed in Fig. 1. The system is composed of a single-chip microcomputer module, sensor module, controller module, serial communication module, and LabVIEW software interface.

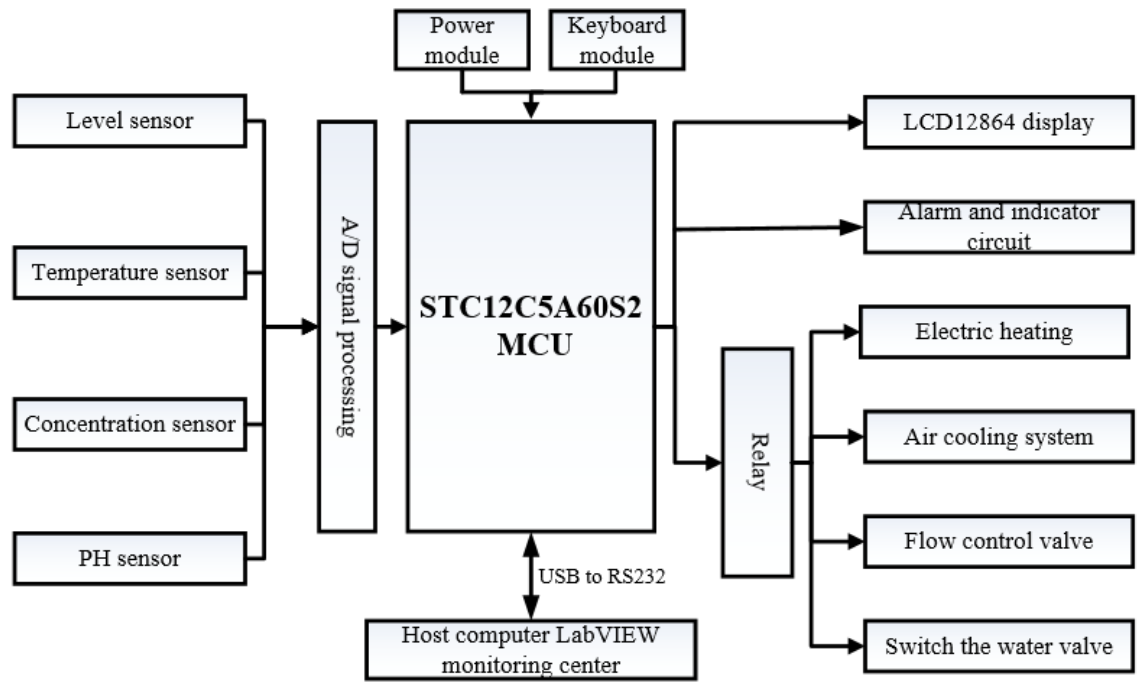

Fig. 1 Block diagram of the proposed system.

The block diagram of the control system for each factor in the conjunctival pool is illustrated in Fig. 2. First, the analog signal measured by each sensor is transmitted to the single-chip microcomputer through analog-to-digital (A/D) signal processing. The single-chip microcomputer controls the liquid crystal (LCD) module, alarm module, and relay module. Finally, to set the value range for each factor, a set of instructions can be input into the microcontroller. For example, consider the temperature factor; if the temperature is lower than the set lower limit, the single-chip microcomputer controls electric heating through a relay to increase the temperature; if the temperature is higher than the upper limit, the microcontroller can control the air cooling system above the conjunctival tank to reduce the temperature of the slurry surface. Furthermore, if the slurry level is lower or higher than the set liquid level, the single-chip microcomputer controls the flow control valve through a relay, which can speed up or inhibit the flow of slurry into the conjunctival tank. To change the level of the slurry in the conjunctival pool, if the concentration and $\mathrm{PH}$ value of the slurry are not within the set range, the volume of the slurry in the conjunctival pool can be controlled using the on-off valve in order to adjust the slurry concentration and $\mathrm{PH}$.

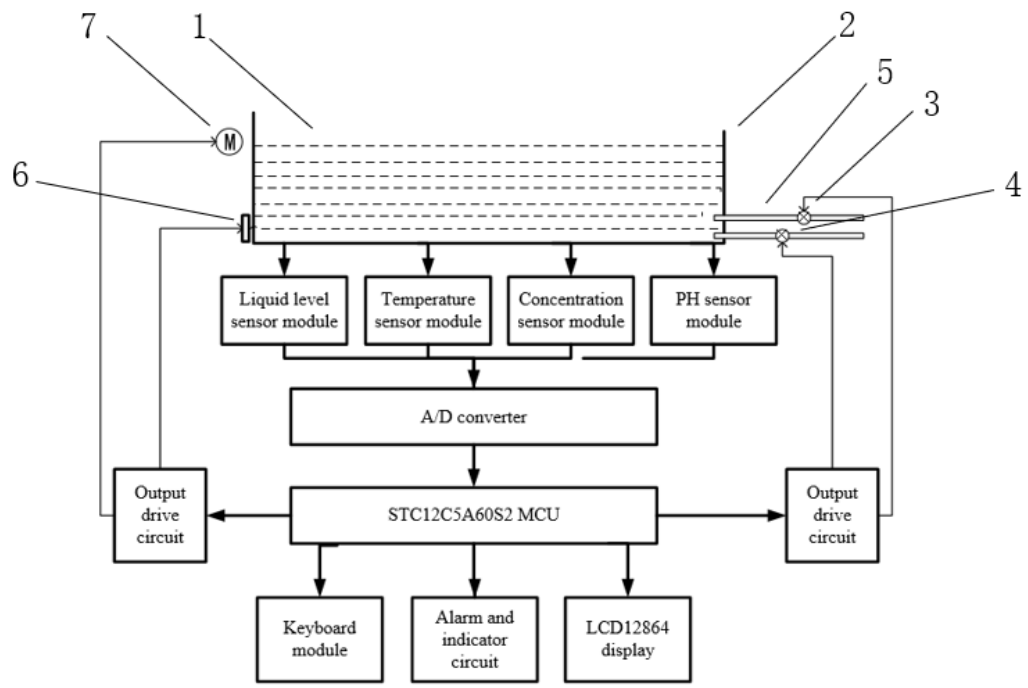

Fig. 2 Block diagram of the control system for every factor in the conjunctival cistern. Where, the number1 is Slurry level; The number 2 is Conjunctival cistern; The number 3 is Flow control valve; The number 4 is Switch water valve; The number 5 is pipeline; The number 6 is Electric heating; The number 7 is Air cooling system. 


\section{Multifactor control system design}

\subsection{Hardware design}

\subsubsection{STC12C5A60S2 system module}

The STC12C5A60S2 main control module comprises an enhanced $8051 \mathrm{CPU}$, which is a single-clock/machine cycle (1T) single-chip microcomputer with a working frequency of 0-35 MHZ (Hercog et al., 2014; Yu, 2020). The functions of the single-chip microcomputer STC12C5A60S2 module are outlined as follows: (1) accept the analog signal collected by the sensor and process it after conversion; (2) control the valve, motor, and electric heating through the output drive circuit; (3) control the external keyboard, alarm, and display module; and (4) receive, send, and process information through the serial port.

The single-chip module (SCM) system primarily comprises the SCM, reset circuit, and crystal oscillator circuit. The system requires a 5-V DC power supply. The step-down circuit uses an LM78M05CH step-down regulator chip and has a perfect overheat and short-circuit protection circuit. The output current can reach $0.5 \mathrm{~A}$, and the output voltage can reach 5 , 6 , 8, 12, 15, 18, and $24 \mathrm{~V}$ (Husain et al., 2016; Wang et al., 2010). The rectifier circuit uses a bridge rectifier, and the unidirectional conductivity of the diode can be used to convert AC into DC (Li, 2013; Tylavsky and Trutt, 2007). The circuit diagrams of the SCM and power supply module are presented in Figs. 3 and 4., respectively.

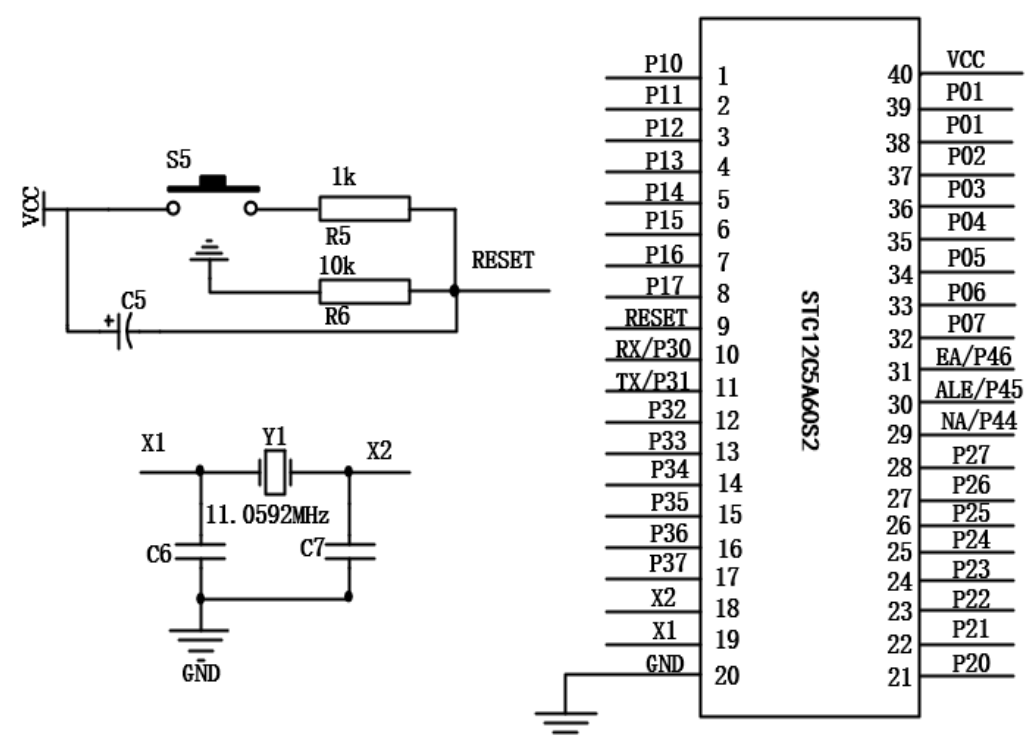

Fig. 3 SCM circuit diagram.

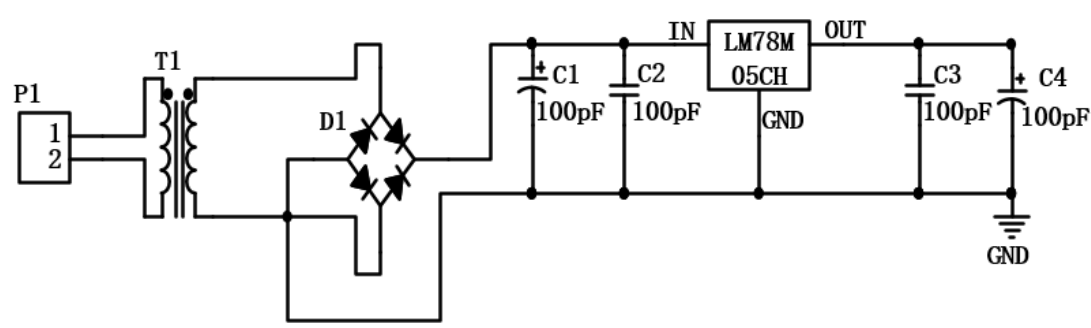

Fig. 4 Power supply module circuit diagram.

\subsubsection{Sensor modules}

The temperature measurement module of the system comprises a compact low-cost digital temperature sensor, namely 
DS18B20, which outputs a digital signal and exhibits strong anti-interference ability and high precision. The measurement range is from -55 to $+125^{\circ} \mathrm{C}$, and a single bus is available for data communication.

The slurry level measurement module comprises an ultrasonic distance measuring sensor, namely HC-SR04, with a measurement range of 2-400 cm. The module consists of an ultrasonic transmitter, a receiver, and a control circuit. The HC-SR04 module has four lead interfaces: VCC, GND, Trig, and Echo. The VCC interface is a 5-V power supply, GND interface is ground, Trig interface triggers the control signal input, Echo interface is the signal output.

The slurry PH measurement module comprises a PH composite electrode (E-201-C), which exhibits fast response, accurate measurement, and excellent stability and is difficult to hydrolyze. The electrode is connected to the single-chip microcomputer through the BNC interface for data collection.

The slurry concentration measurement module comprises an ultrasonic concentration sensor (KF-102). Signals fed back from the transmitter and receiver probes are transmitted to the microcontroller through a two-stage dual operational amplifier, and the microcontroller converts the signals into corresponding concentration values. The schematic of the sensor measurement module circuit is displayed in Fig. 5. The specifications of each sensor are shown in Table 1.

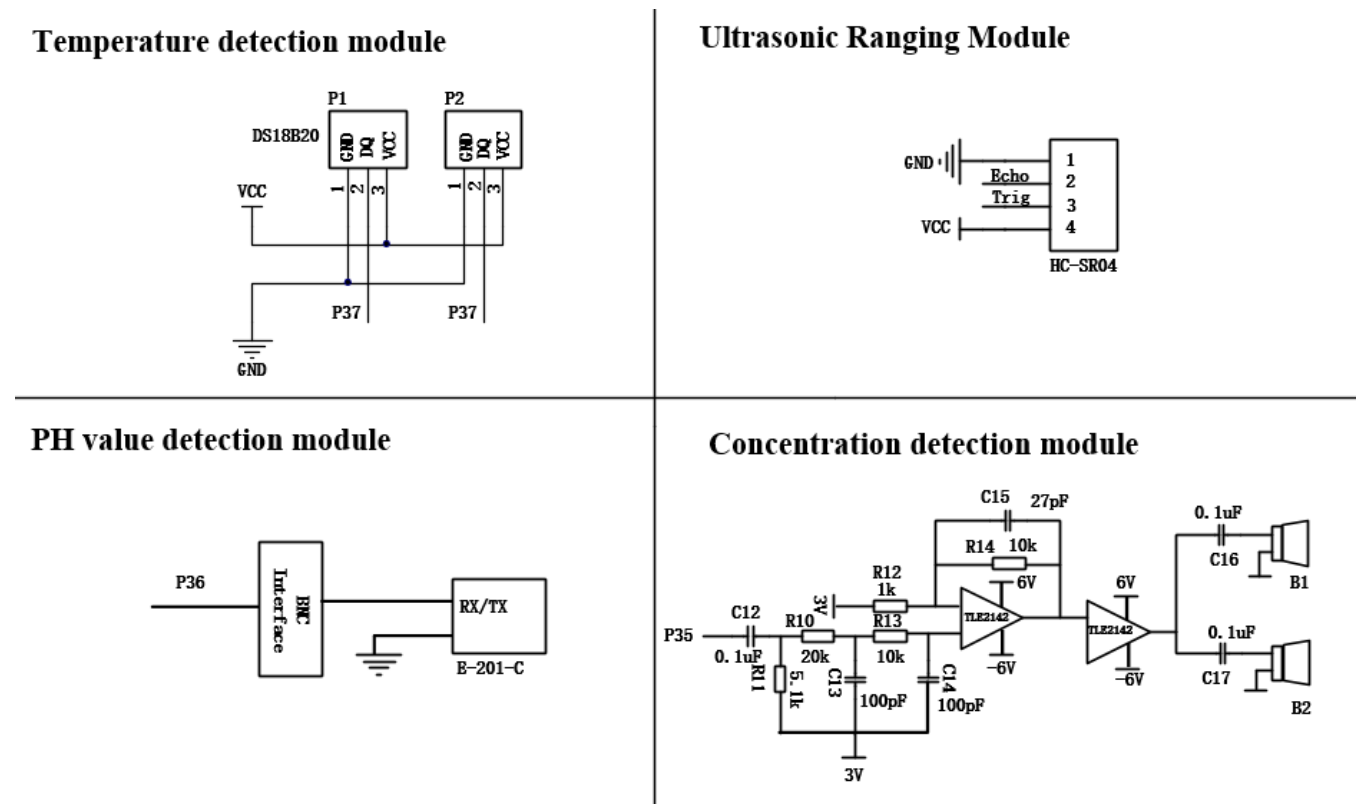

Fig. 5 Sensor module circuit.

Table 1 The specifications of sensors.

\begin{tabular}{cccc}
\hline Sensors & Model & Range & Characteristic of the Sensor \\
\hline Temperature Sensor & DS18B20 & $-55^{\circ} \mathrm{C} \sim+125^{\circ} \mathrm{C}$ & The structure is simple and the power supply mode is flexible. \\
Liquid level Sensor & HC-SR04 & $20 \mathrm{~mm} \sim 45000 \mathrm{~m}$ & Stable performance, accurate ranging, and low price. \\
PH Sensor & E-201-C & $0 \sim 14$ & The response is fast and the electrode is rechargeable. \\
Concentration Sensor & KF-102 & $0 \sim 100 \%$ & Non-contact measurement, measurement accuracy $0.2 \%$ \\
\hline
\end{tabular}

\subsubsection{Multifactor control module}

Heaters and cold winds are used for slurry heating and cooling, respectively. A value is used to control the flow of the slurry in the pipeline in order to maintain the desired slurry level. The model of the valve is G641J, The main parameters are shown in Table 2. Two water valves are connected between the slurry storage pool and conjunctival pool. The opening of the water valves is controlled to adjust the concentration and $\mathrm{PH}$ of the slurry in the conjunctival pool. The model of the water valves is HOPE62-32, The main parameters are shown in Table 3. The schematic of the multifactor control module circuit is illustrated in Fig 6. 


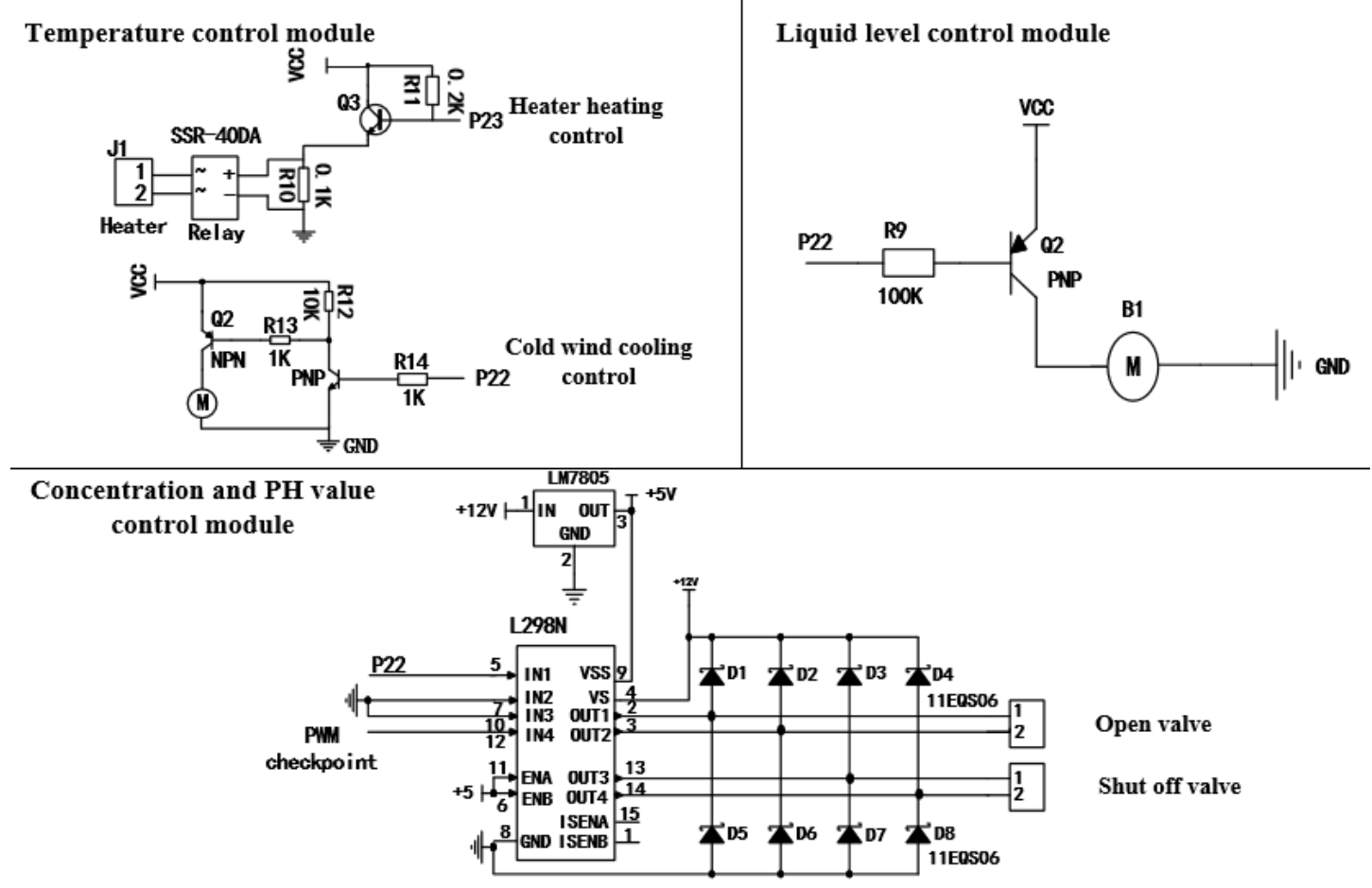

Fig. 6 Multifactor control module circuit.

Table 2 The main parameters of G641J

\begin{tabular}{cccccc}
\hline Name & $\begin{array}{c}\text { Valve seat } \\
\text { Diameter }\end{array}$ & $\begin{array}{c}\text { Nominal } \\
\text { Diameter }\end{array}$ & $\begin{array}{c}\text { Rated Flow } \\
\text { Coefficient }\end{array}$ & $\begin{array}{c}\text { Nominal } \\
\text { Pressure }\end{array}$ & $\begin{array}{c}\text { Operating } \\
\text { Temperature }\end{array}$ \\
\hline Parameter & $\mathrm{dn} 12 \mathrm{~mm}$ & DN20mm & $2.8 \mathrm{kv}$ & PN1.6Mpa & $-20 \sim 200^{\circ} \mathrm{C}$ \\
\hline
\end{tabular}

Table 3 The main parameters of HOPE62-32

\begin{tabular}{ccccccc}
\hline \multirow{2}{*}{ Name } & Operating & Nominal & Way to & Body & Standard & Installation \\
& Voltage & Diameter & Control & Material & Voltage & Method \\
\hline \multirow{2}{*}{ Parameter } & $0-1.0 \mathrm{Mpa}$ & DN32mm & Normally & Stainless & DC24V & Horizontal \\
& & & Closed & Steel & & Hnstallation \\
\hline
\end{tabular}

\subsection{System software design}

\subsubsection{Software design of the lower computer}

C language modular programming was used to design the system program initialization module, button setting module, LCD12864 module, timer interrupt program module, A/D conversion module, ultrasonic liquid level measurement module, temperature measurement module, concentration measurement module, $\mathrm{PH}$ value measurement module, motor, and water valve control module.

Once the module is powered on, the microcontroller is initialized, and data from each sensor are collected using the A/D converters. The value of each factor is then displayed by the LCD12864 module after microcontroller processing, and the collected current value and the set value are compared and analyzed accordingly. If the value does not meet the set range, an alarm is triggered and the control swings into action; if the value meets the set range, then the collection and comparison are performed again, and finally, the control of the system is realized. The flowchart of the software design is shown in Fig. 7. 


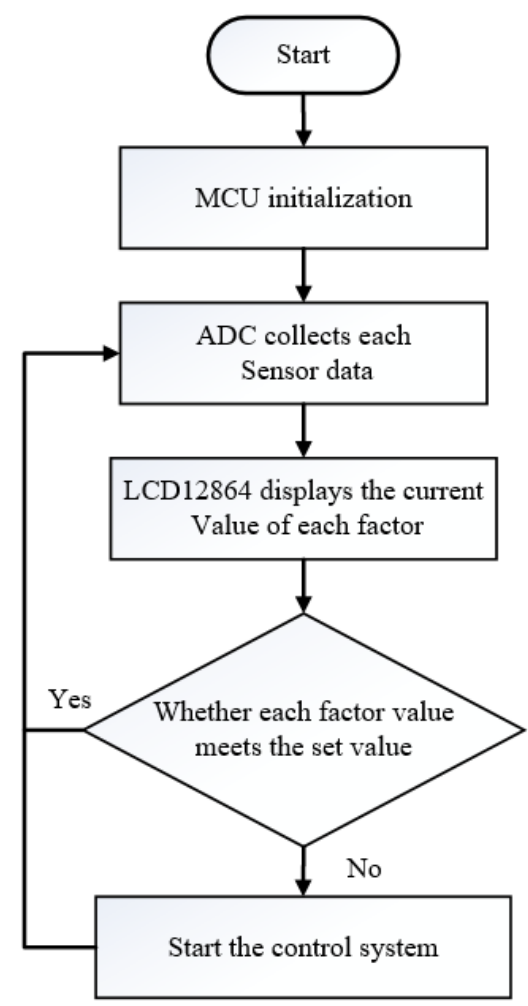

Fig. 7 Flowchart of the software design of lower computer

\subsubsection{Host computer software design}

The upper computer uses LabVIEW, the graphical programming software program developed by National Instruments, to record the slurry temperature, slurry level, slurry concentration, slurry $\mathrm{pH}$, and wind speed above the conjunctival tank. The host computer LabVIEW acquisition interface is displayed in Fig. 8. The VISA function in LabVIEW is used to realize serial port control. The serial port control system primarily entails configuring, reading, writing, and closing the serial port. First, the serial port is configured as follows: the serial port number is set to COM1; baud rate is set to 9600; and number of data bits is set to 8 bits, with 1 stop bit and no parity bit. Subsequently, a while loop is implemented to prevent the program from stopping for a long time; the VISA function is used to read the attribute nodes of the serial port by using bytes at the port in the middle. The serial port data are then read, and the value of each multifactor is read. Finally, the serial port is closed.

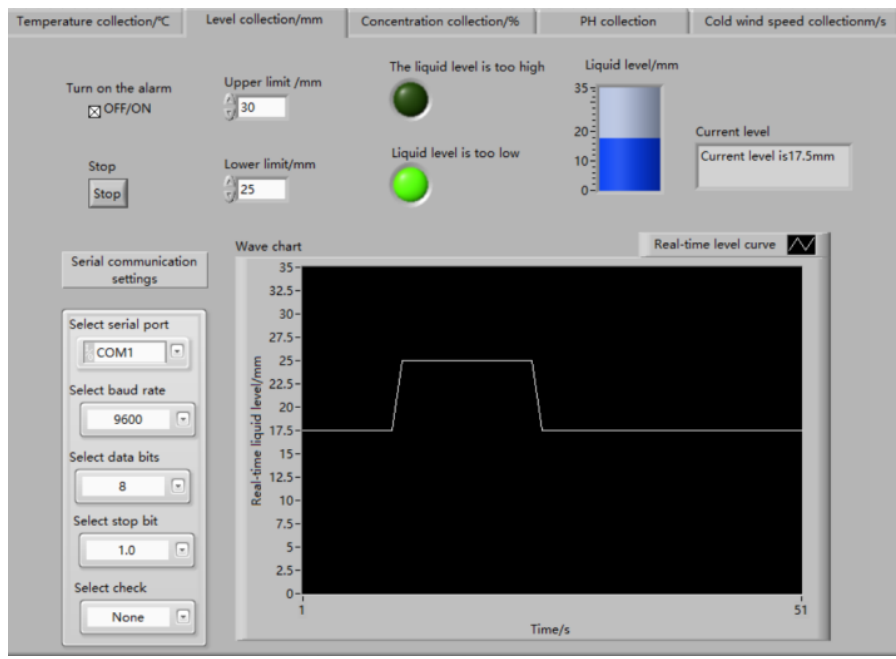

Fig. 8 LabVIEW acquisition interface. 


\subsubsection{Fuzzy PID control design}

Fuzzy PID control is to combine conventional PID with fuzzy theory, and use Mamdani fuzzy inference to optimize PID parameters according to the set fuzzy rules. The block diagram of the fuzzy PID controller is shown in Fig. 9. In the figure, $r(t)$ is the system setting parameter, and $y(t)$ is the parameter value of various factors in the yuba conjunctival pool. The system takes the deviation e between the set parameter and the actual parameter and the deviation change rate ec as input, and uses the three parameters $\triangle \mathrm{Kp}, \triangle \mathrm{Ki}$, and $\triangle \mathrm{Kd}$ as the output of the fuzzy control system. These three output parameters are adjusted online for PID control. There are three parameters: the proportional coefficient $\mathrm{Kp}$, the integral coefficient $\mathrm{Ki}$, and the differential coefficient $\mathrm{Kd}$.

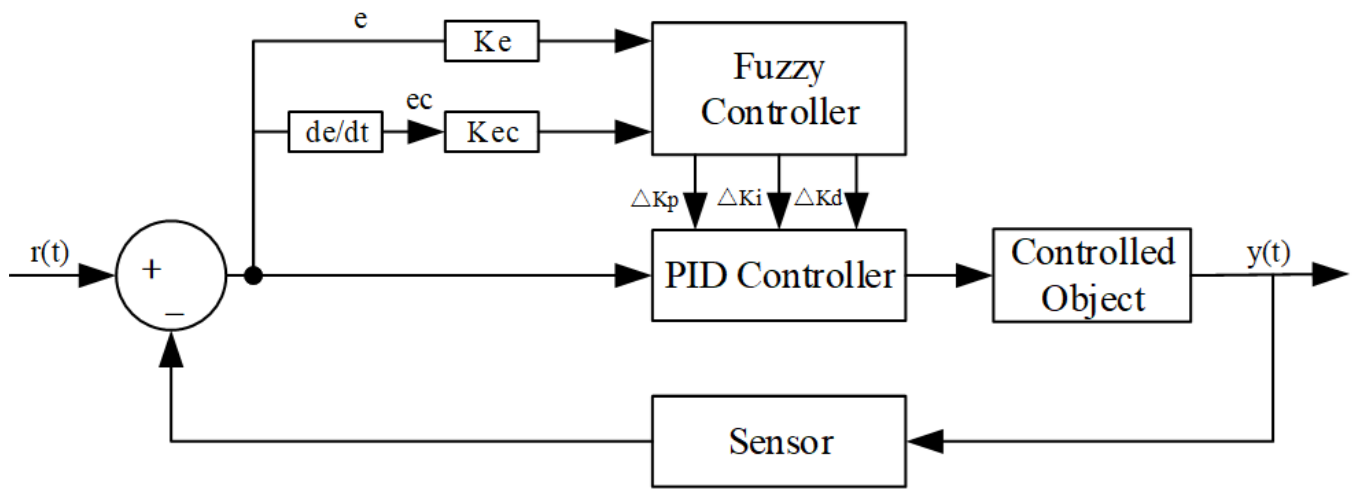

Fig. 9 Fuzzy PID controller structure diagram

Considering the response speed, overshoot, steady-state error, adjustment time, stability, etc. of the control system, a PID parameter adjustment rule table is established based on expert experience, as shown in table 4,5,6.

Table $4 \mathrm{P}$ parameter adjustment rule table

\begin{tabular}{|c|c|c|c|c|c|c|c|c|}
\hline \multirow{2}{*}{\multicolumn{2}{|c|}{$\triangle \mathrm{Kp}$}} & \multicolumn{7}{|c|}{ ec } \\
\hline & & NB & NM & NS & $\mathrm{ZO}$ & PS & $\mathrm{PM}$ & PB \\
\hline \multirow{7}{*}{ e } & NB & PB & PB & PM & PM & PS & $\mathrm{ZO}$ & $\mathrm{ZO}$ \\
\hline & NM & PB & PB & PM & PS & PS & ZO & NS \\
\hline & NS & PM & PM & PM & PS & ZO & NS & NS \\
\hline & ZO & PM & PM & PS & ZO & NS & NM & NM \\
\hline & PS & PS & PS & ZO & NS & NS & NM & NM \\
\hline & PM & PS & ZO & NS & NM & NM & NM & NB \\
\hline & PB & ZO & ZO & NM & NM & NM & NB & NB \\
\hline \multicolumn{9}{|c|}{ Table 5 I parameter adjustment rule table } \\
\hline \multirow{2}{*}{\multicolumn{2}{|c|}{$\triangle \mathrm{Ki}$}} & \multicolumn{7}{|c|}{ ec } \\
\hline & & NB & NM & NS & $\mathrm{ZO}$ & PS & PM & PB \\
\hline \multirow{7}{*}{ e } & NB & NB & NB & NM & NM & NS & ZO & ZO \\
\hline & NM & NB & NB & NM & NS & NS & zO & ZO \\
\hline & NS & NB & NM & NS & NS & ZO & PS & PS \\
\hline & ZO & NM & NM & NS & ZO & PS & PM & PM \\
\hline & PS & NM & NS & ZO & PS & PS & PM & PB \\
\hline & PM & ZO & ZO & PS & PS & PM & PB & PB \\
\hline & PB & ZO & ZO & PS & PM & PM & PB & PB \\
\hline
\end{tabular}


$\mathrm{Xu}$, Dai, Shen, Yang, Jiang and Tang,

Journal of Advanced Mechanical Design, Systems, and Manufacturing, Vol.15, No.5 (2021)

Table 6 D parameter adjustment rule table

\begin{tabular}{|c|c|c|c|c|c|c|c|c|}
\hline & \multirow{2}{*}{$\triangle K d$} & \multicolumn{7}{|c|}{ ec } \\
\hline & & NB & NM & NS & ZO & PS & PM & PB \\
\hline \multirow{7}{*}{ e } & NB & PS & NS & NB & NB & NB & NM & PS \\
\hline & NM & PS & NS & NB & NM & NM & NS & ZO \\
\hline & NS & ZO & NS & NM & NM & NS & NS & ZO \\
\hline & ZO & ZO & NS & NS & NS & NS & NS & ZO \\
\hline & PS & ZO & ZO & ZO & ZO & ZO & ZO & ZO \\
\hline & PM & PB & PS & PS & PS & PS & PS & PB \\
\hline & PB & PB & PM & PM & PM & PS & PS & PB \\
\hline
\end{tabular}

According to the fuzzy control rule table, the Mamdani method is used for reasoning. The fuzzy relationship matrix is taken to obtain the three-dimensional diagram of the $\triangle \mathrm{Kp}, \triangle \mathrm{Ki}$, and $\triangle \mathrm{Kd}$ control rules, as shown in Fig.10.

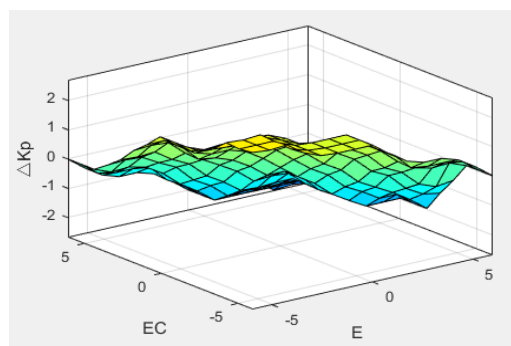

(a) $\triangle \mathrm{Kp}$ Control rule graph

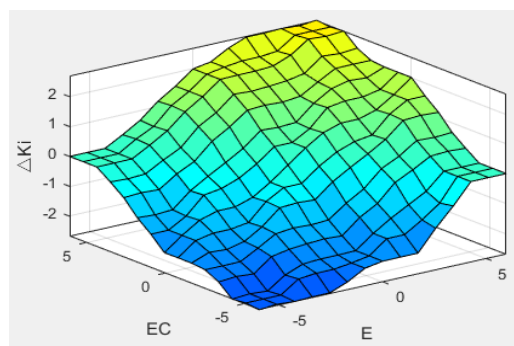

(b) $\triangle \mathrm{Ki}$ Control rule graph

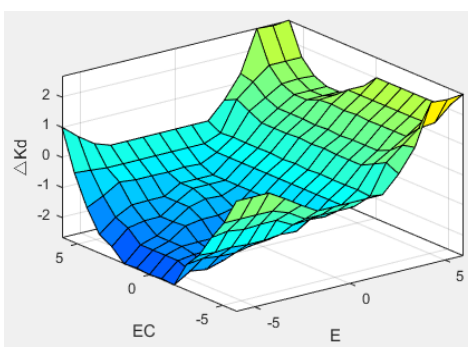

(c) $\triangle \mathrm{Kd}$ Control rule graph

Fig. 10 3D diagram of control rules

On the basis of fuzzy rules, the adjusted fuzzy quantities $\triangle \mathrm{Kp}, \triangle \mathrm{Ki}, \triangle \mathrm{Kd}$ are calculated by reasoning. The center of gravity method and the weighted average method are used to convert the fuzzy amount into the actual value. The actual value and the current system parameter values $\mathrm{Kp}^{\prime}, \mathrm{Ki}^{\prime}, \mathrm{Kd}^{\prime}$ are added to obtain the three parameters $\mathrm{Kp}, \mathrm{Ki}, \mathrm{Kd}$ after real-time adjustment of the system.

$$
\left\{\begin{array}{c}
\mathrm{Kp}=K \mathrm{~K}^{\prime}+\Delta \mathrm{Kp} \\
\mathrm{Ki}=\mathrm{Ki}^{\prime}+\Delta \mathrm{Ki} \\
\mathrm{Kd}=\mathrm{Kd}^{\prime}+\Delta \mathrm{Kd}
\end{array}\right.
$$

Finally, the mathematical model of the controller and the Simulink model diagram are obtained. It can be obtained from the figure that the time constant $\mathrm{T}$ of the system is $90 \mathrm{~s}$, and the lag time $\tau$ is $5 \mathrm{~s}$.

$$
\mathrm{G}(\mathrm{s})=\frac{1.25 \cdot \mathrm{e}^{-5 \mathrm{~s}}}{90 \mathrm{~s}+1}
$$




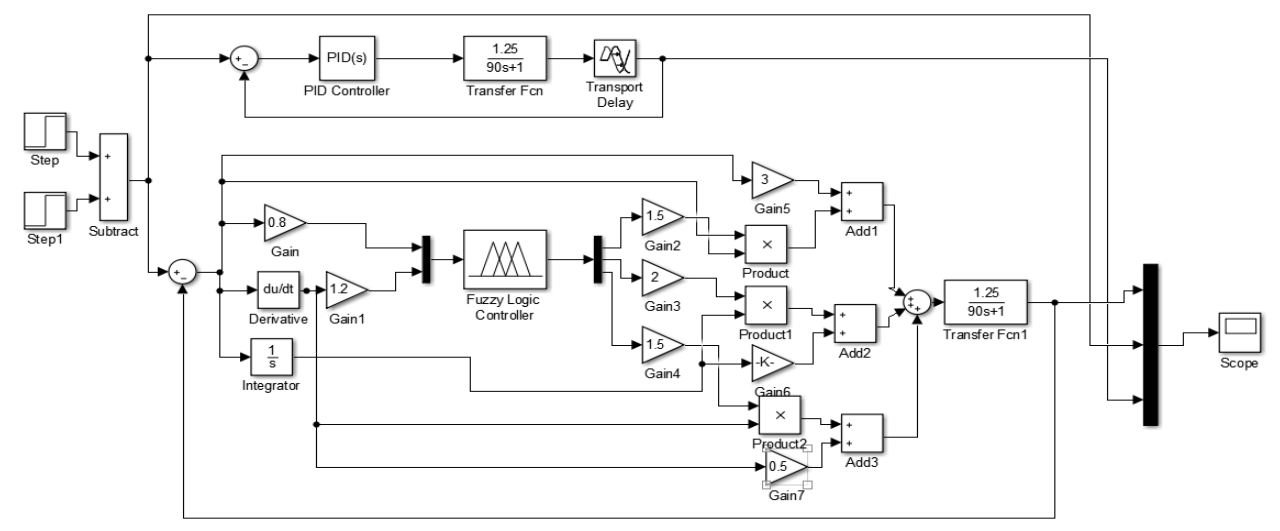

Fig. 11 Simulink model diagram

\subsection{System construction and debugging}

The test platform was constructed as displayed in Fig. 12, and the system was debugged and analyzed.

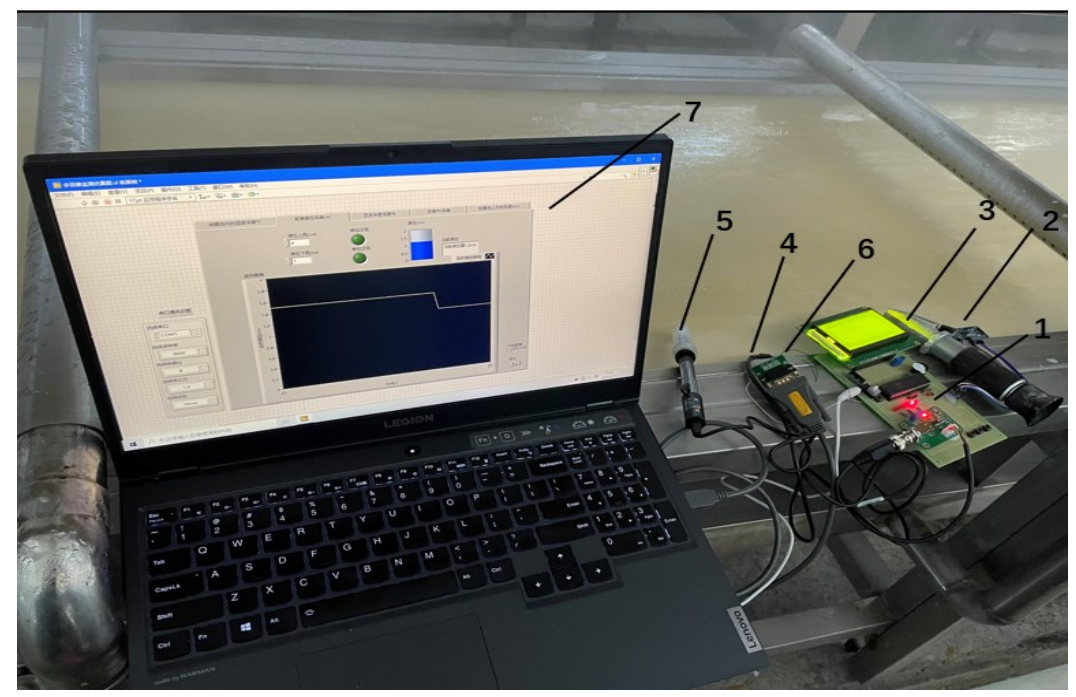

Fig. 12 Experimental test platform. Where, the number 1 is Microcontroller; The number 2 is Liquid level sensor; The number 3 is Concentration sensor; The number 4 is Temperature sensor; The number 5 is PH controller; The number 6 is USB to RS232; The number 7 is Host computer LabVIEW monitor.

First, the signal acquisition and amplification circuit were debugged. This process primarily entailed adjusting the amplification factor for accurate acquisition of information. Second, the multimeter was connected to the A/D channel of the single-chip microcomputer to view the output voltage change and debug the circuit. The measured voltage value was compared with the quantized digital value, and the error in the quantization process was corrected. Finally, the serial communication module was debugged. The serial port was used to send and receive data to and from the microcontroller to evaluate whether the results were consistent. The measurement results for various factors after the final debugging were analyzed as follows: 


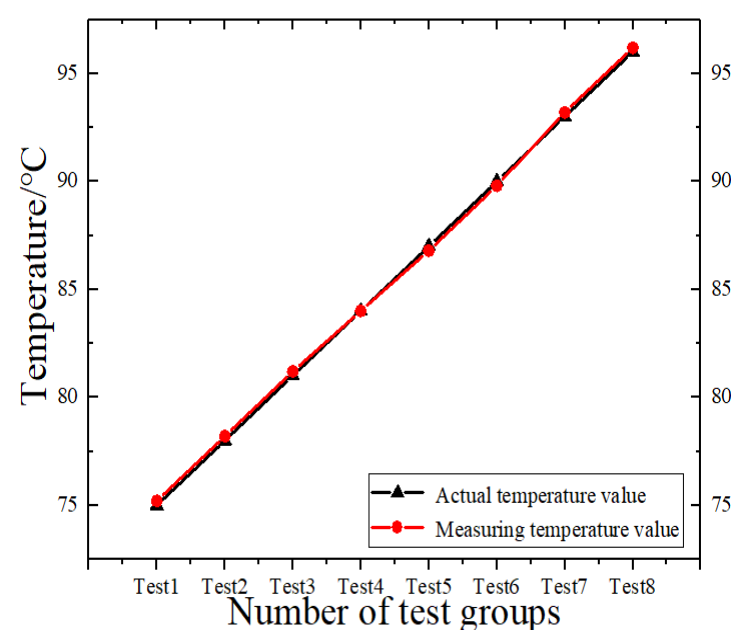

(a) Temperature error comparison

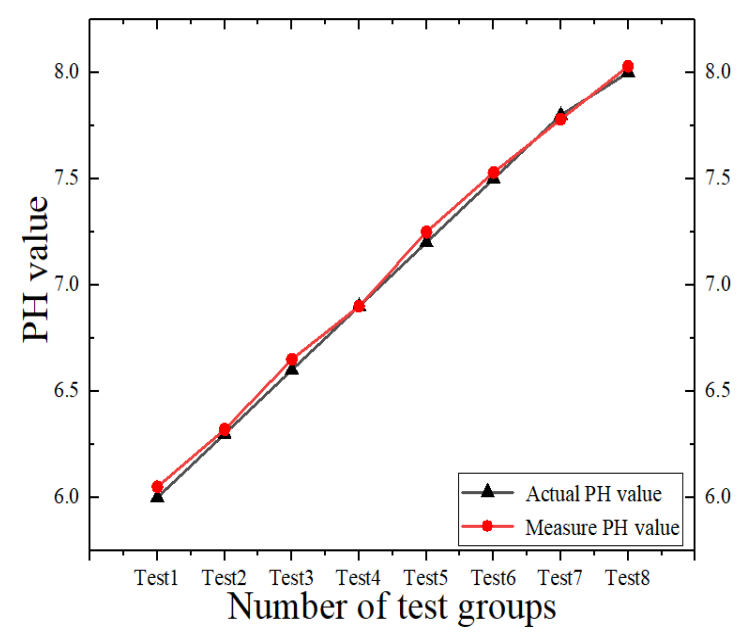

(c) $\mathrm{PH}$ value error comparison

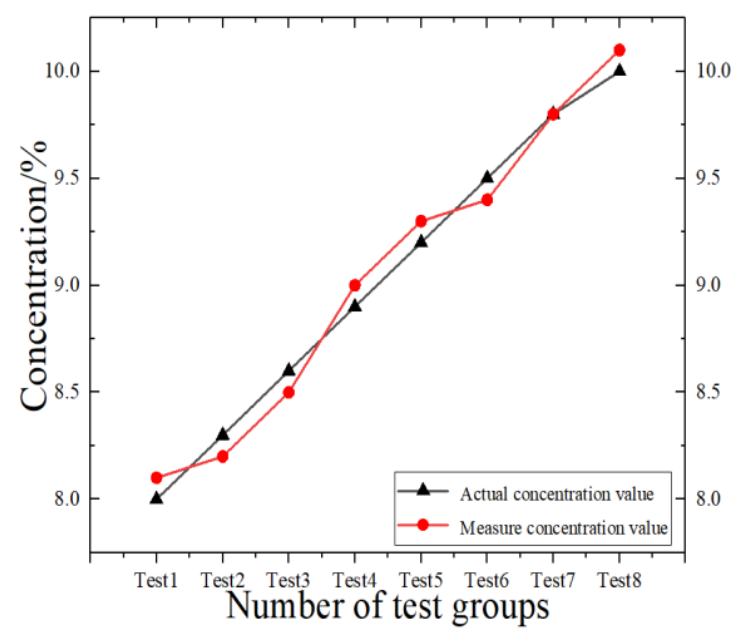

(b) Concentration error comparison

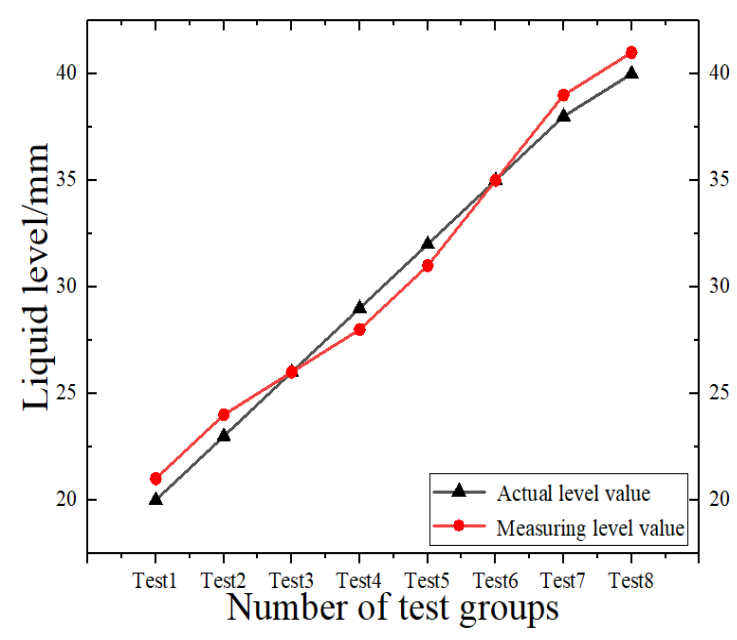

(d) Liquid level error comparison

Fig. 13 Analysis of measurement results of various factors.

To verify the data collection accuracy of each sensor, data measured by standard instruments and sensors were used for a comparative analysis. As illustrated in Fig. 13(a), the measured temperature was within $0.2{ }^{\circ} \mathrm{C}$ of the actual temperature. As displayed in Fig. 13(b), the measured concentration was within $0.1 \%$ of the actual concentration. Moreover, as presented in Fig, 13(c), the measured PH value was within 0.05 of the actual PH value. Finally, as shown in Fig. 13(d), the measured liquid level was within $1 \mathrm{~mm}$ of the actual level. Thus, the system error does not affect the continuous film-forming of yuba, which satisfies the design requirements.

\section{Orthogonal test optimization analysis}

\subsection{Orthogonal experimental model establishment and variance analysis}

To determine the optimized yuba production conditions, this study selected four factors for orthogonal test analysis, namely slurry temperature $\left(X_{a}\right)$, liquid level $\left(X_{b}\right)$, concentration $\left(X_{c}\right)$, and $\mathrm{PH}\left(X_{d}\right)$. Several tests were conducted for each factor, after which the average was derived. The yield of yuba was the evaluation standard for the test results. The yield of yuba was calculated according to Eq. (3), where $\mathrm{Y}$ is the yield of yuba, $\mathrm{M}$ is the quantity of dried yuba, and $\mathrm{G}$ is the quality of dried soybeans used in the test. The test measurement diagram is displayed in Fig. 14. First, conduct a single factor experiment to obtain a graph of the effect of each factor of the slurry on the yield of yuba in Fig.15. Then, select the appropriate parameter change range according to the single factor change to conduct a multifactor test. The design scheme and results of the orthogonal experiment are displayed in Table 7. 
$\mathrm{Xu}$, Dai, Shen, Yang, Jiang and Tang,

Journal of Advanced Mechanical Design, Systems, and Manufacturing, Vol.15, No.5 (2021)

$Y=\frac{M}{G} \times 100 \%$

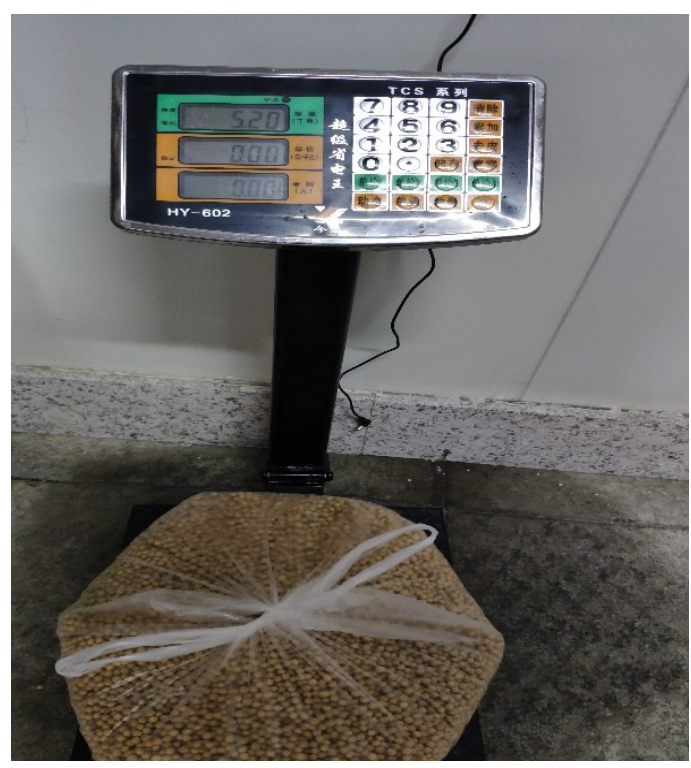

(a) The quality of dried soybeans

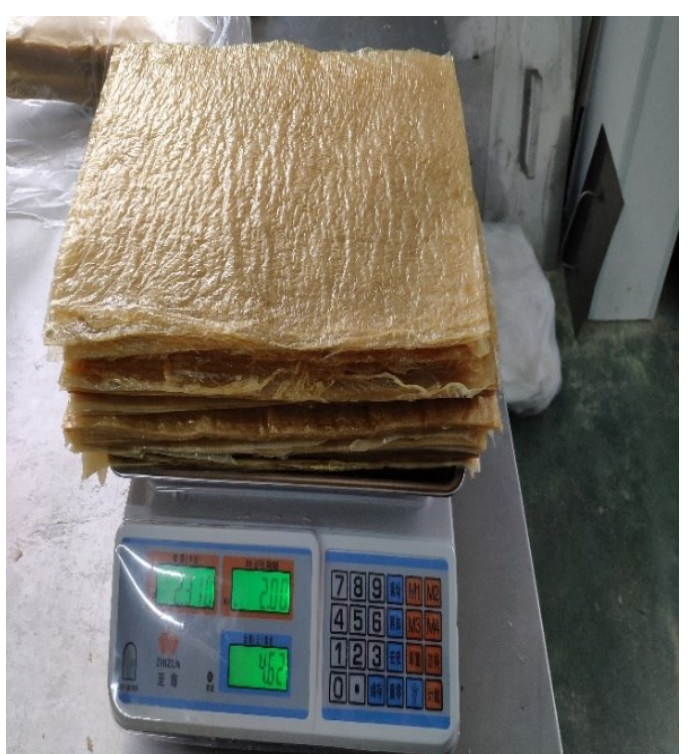

(b) The quantity of dried yuba

Fig.14 Test measurement chart.

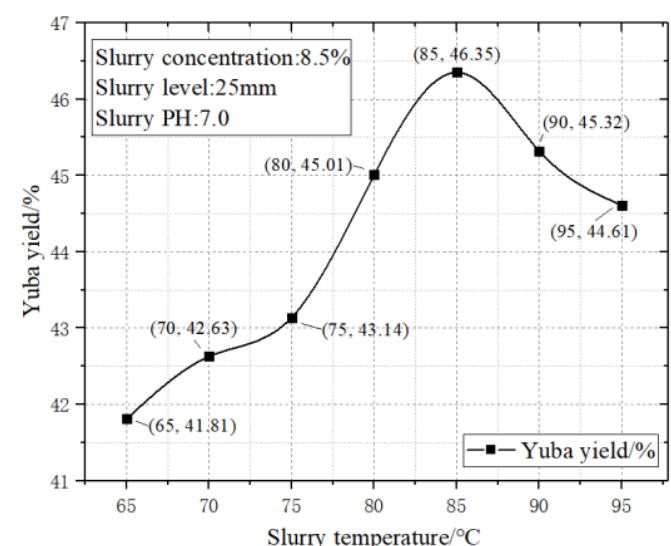

(a) The effect of slurry temperature on the yield of yuba

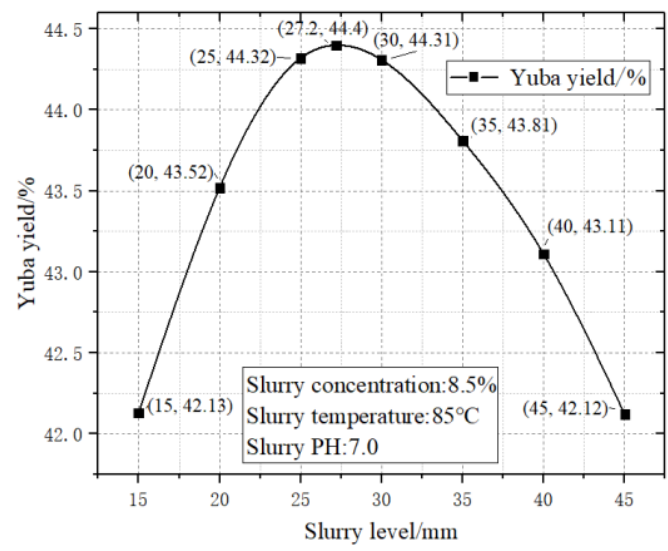

(c) The effect of slurry level on the yield of yuba

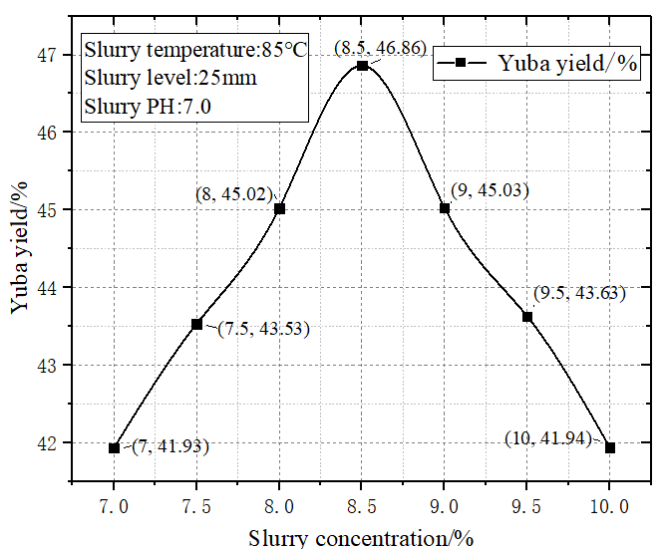

(b) The effect of slurry concentration on the yield of yuba

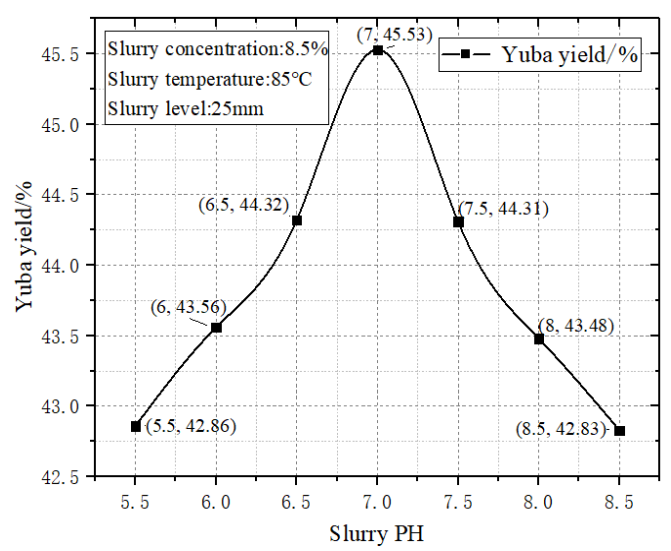

(d) The effect of slurry PH on the yield of yuba

Fig.15 The effect of each factor of slurry on the yield of yuba 
$\mathrm{Xu}$, Dai, Shen, Yang, Jiang and Tang,

Journal of Advanced Mechanical Design, Systems, and Manufacturing, Vol.15, No.5 (2021)

Table 7 Design scheme and results of orthogonal experiment.

\begin{tabular}{|c|c|c|c|c|c|}
\hline Test number & $X_{a}:$ Temperature $/{ }^{\circ} \mathrm{C}$ & $X_{b}$ : Liquid level $/ \mathrm{mm}$ & $X_{\mathrm{c}}:$ concentration $/ \%$ & $X_{d}: \mathrm{PH}$ & $Y$ : Yuba yield $/ \%$ \\
\hline 1 & 95 & 40 & 10 & 8 & 44.21 \\
\hline 2 & 75 & 40 & 10 & 6 & 42.33 \\
\hline 3 & 75 & 20 & 8 & 6 & 44.09 \\
\hline 4 & 85 & 30 & 9 & 6 & 45.21 \\
\hline 5 & 95 & 20 & 8 & 6 & 44.93 \\
\hline 6 & 85 & 30 & 9 & 7 & 47.86 \\
\hline 7 & 75 & 20 & 10 & 6 & 42.31 \\
\hline 8 & 85 & 30 & 9 & 7 & 47.85 \\
\hline 9 & 75 & 40 & 8 & 8 & 42.31 \\
\hline 10 & 75 & 40 & 8 & 6 & 43.61 \\
\hline 11 & 75 & 20 & 10 & 8 & 43.03 \\
\hline 12 & 75 & 40 & 10 & 8 & 44.39 \\
\hline 13 & 85 & 30 & 8 & 7 & 43.72 \\
\hline 14 & 75 & 20 & 8 & 8 & 42.23 \\
\hline 15 & 95 & 20 & 10 & 8 & 43.97 \\
\hline 16 & 95 & 40 & 10 & 6 & 41.33 \\
\hline 17 & 95 & 20 & 10 & 6 & 41.53 \\
\hline 18 & 95 & 40 & 8 & 8 & 43.96 \\
\hline 19 & 95 & 40 & 8 & 6 & 45.22 \\
\hline 20 & 85 & 40 & 9 & 7 & 47.23 \\
\hline 21 & 95 & 20 & 8 & 8 & 44.26 \\
\hline
\end{tabular}

Quadratic regression fitting was performed on the results (Table 7) to obtain the following regression equation:

$$
\begin{aligned}
& Y=47.81+0.32 X_{a}+0.063 X_{b}-0.47 X_{c}+0.19 X_{d}-0.059 X_{a} X_{b}-0.45 X_{a} X_{c}+0.24 X_{a} X_{d} \\
& +0.11 X_{b} X_{c}+0.11 X_{b} X_{d}+0.82 X_{c} X_{d}+3.25 X_{a}^{2}-0.69 X_{b}^{2}-4.6 X_{c}^{2}-2.46 X_{d}^{2}
\end{aligned}
$$

The variance analysis table is presented in Table 8 , where $C=X^{2}$ is the correction number, $\mathrm{n}$ is the number of samples, and $\mathrm{k}$ is the number of test levels (Peerkhan and Nair, 2020; Xu and He, 2010; Mervyn et al., 2018; Dunn and Clark, 2015).

Table 8 Variance formula analysis table.

\begin{tabular}{ccccc}
\hline Source of Variance & $S S$ & $d f$ & $M S$ & $F$ \\
\hline Processing room & $S S_{\mathrm{t}}=\frac{1}{\mathrm{n}} \sum_{\mathrm{i}=1}^{\mathrm{k}} \mathrm{x}_{\mathrm{i}}^{2}-C$ & $\mathrm{df}_{\mathrm{t}}=\mathrm{k}-1$ & $M S_{\mathrm{t}}=\frac{S S_{\mathrm{t}}}{\mathrm{df}_{\mathrm{t}}}$ & $F=\frac{M S_{\mathrm{t}}}{M S_{\mathrm{e}}}$ \\
Residual & $S S_{\mathrm{e}}=S S_{\mathrm{T}}-S S_{\mathrm{t}}$ & $\mathrm{df}_{\mathrm{e}}=\mathrm{df}_{T}-\mathrm{df}_{\mathrm{t}}$ & $M S_{\mathrm{e}}=\frac{S S_{\mathrm{e}}}{\mathrm{df}_{\mathrm{e}}}$ & $/$ \\
Total error & $S S_{\mathrm{T}}=\sum_{\mathrm{i}=1}^{\mathrm{k}} \sum_{\mathrm{j}=1}^{\mathrm{n}} \mathrm{x}_{\mathrm{ij}}^{2}-C$ & $\mathrm{df}_{T}=\mathrm{nk}-1$ & $/$ & $/$ \\
\hline
\end{tabular}

The variance analysis table was analyzed using a regression model, as presented in Table 9. As indicated in this table, the response surface analysis results for this regression model differed significantly in terms of the influence of the various factors $(\mathrm{P}=0.0001)$. Accordingly, the factors can be ordered as follows with respect to their influence on the yield of yuba: slurry concentration $>$ slurry temperature $>$ slurry $\mathrm{PH}>$ slurry level. In the model, the influence of $X_{c}, X_{a} X_{c}, X_{c} X_{d}, X_{a}^{2}, X_{c}^{2}$, and $X_{d}^{2}$ on the yield of yuba was extremely significant, and the influence of $X_{a}$ and $X_{a} X_{d}$ on the yield of yuba was significant. This 
model exhibited a good fit with the actual test data. Therefore, the regression equation can be used to replace the actual test for evaluation and analysis.

Table 9 Regression model analysis of the variance table.

\begin{tabular}{|c|c|c|c|c|c|c|}
\hline Variation source & $S S$ & $d f$ & $M S$ & $F$ & P-value & Significant effect \\
\hline model & 69.40 & 14 & 4.96 & 38.84 & 0.0001 & $* *$ \\
\hline$X_{a}$ & 1.63 & 1 & 1.63 & 12.79 & 0.0117 & $*$ \\
\hline$X_{b}$ & 0.064 & 1 & 0.064 & 0.50 & 0.5062 & l \\
\hline$X_{c}$ & 3.53 & 1 & 3.53 & 27.62 & 0.0019 & $* *$ \\
\hline$X_{d}$ & 0.57 & 1 & 0.57 & 4.44 & 0.0798 & l \\
\hline$X_{a} X_{b}$ & 0.056 & 1 & 0.056 & 0.44 & 0.5309 & l \\
\hline$X_{a} X_{c}$ & 3.2 & 1 & 3.2 & 25.04 & 0.0024 & $* *$ \\
\hline$X_{a} X_{d}$ & 0.89 & 1 & 0.89 & 6.96 & 0.0386 & $*$ \\
\hline$X_{b} X_{c}$ & 0.21 & 1 & 0.21 & 1.64 & 0.2476 & I \\
\hline$X_{b} X_{d}$ & 0.19 & 1 & 0.19 & 1.50 & 0.2666 & l \\
\hline$X_{c} X_{d}$ & 10.87 & 1 & 10.87 & 85.21 & $<0.0001$ & $* *$ \\
\hline$X_{a}^{2}$ & 2.01 & 1 & 2.01 & 15.78 & 0.0073 & $* *$ \\
\hline$X_{b}^{2}$ & 0.30 & 1 & 0.30 & 2.37 & 0.1742 & I \\
\hline$X_{c}^{2}$ & 13.57 & 1 & 13.57 & 106.32 & $<0.0001$ & $* *$ \\
\hline$X_{d}^{2}$ & 3.86 & 1 & 3.86 & 30.27 & 0.0015 & $* *$ \\
\hline Residual & 0.77 & 6 & 0.13 & 1 & I & I \\
\hline Cor total & 70.16 & 20 & / & / & / & l \\
\hline
\end{tabular}

Note: *. The difference is significant $(0.01<\mathrm{P}<0.05)$; **. The difference is extremely significant $(\mathrm{P}<0.01)$;

\subsection{Response surface analysis}

To intuitively reflect the influence of multiple factors on the response value, response surface analysis was performed on the resulting regression model. The response surface diagram of the interaction of the various factors is displayed in Fig. 16. Under the interaction of the two factors, the other two factors are set to the best value under a single factor. (The slurry temperature is $85^{\circ} \mathrm{C}$, the slurry concentration is $8.5 \%$, the slurry level is $27 \mathrm{~mm}$, and the slurry pH is 7.) Figure 16(a) illustrates the response surface diagram of the slurry temperature and slurry level; the maximum response value was $47.88 \%$. Figure 16(b) displays the response surface diagram of the slurry temperature and slurry concentration; the maximum response value was $47.90 \%$. Moreover, Fig. 16(c) presents the response surface diagram of the temperature and slurry pH; the maximum response value was $47.88 \%$. Figure $16(\mathrm{~d})$ shows the response surface diagram of the slurry level and slurry concentration; the maximum response value was $47.91 \%$. Figure $16(\mathrm{e})$ displays the response surface of the slurry level and slurry $\mathrm{pH}$; the maximum response value was $47.87 \%$. Finally, Fig. 16 (f) illustrates the response surface diagram of the slurry concentration and slurry $\mathrm{pH}$; the maximum response value was $47.90 \%$. Thus, the regression model could be used to optimize yuba production conditions. Specifically, if the optimal production conditions involved a slurry concentration of $8.50 \%$, slurry temperature of $85.0^{\circ} \mathrm{C}$, slurry $\mathrm{pH}$ of 7.0 , and slurry level of $27.5 \mathrm{~mm}$, the yuba yield would be $47.91 \%$. 


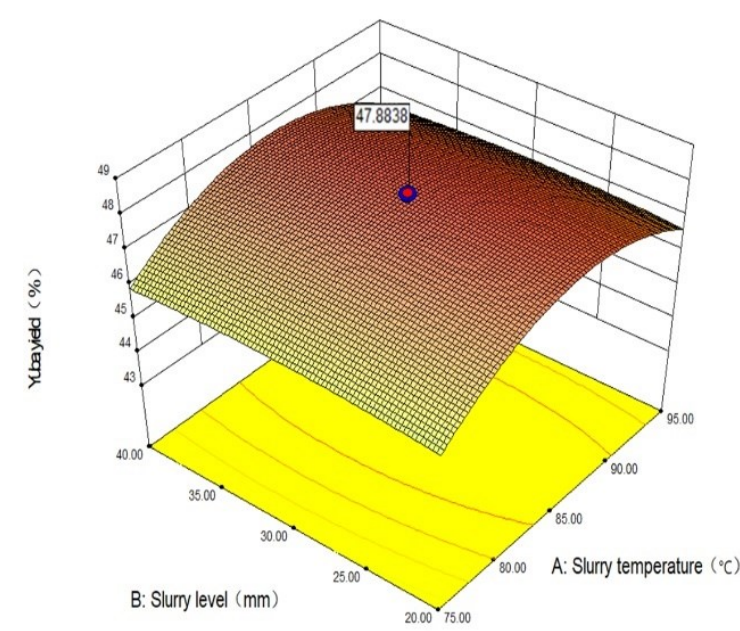

(a) Slurry temperature and slurry level

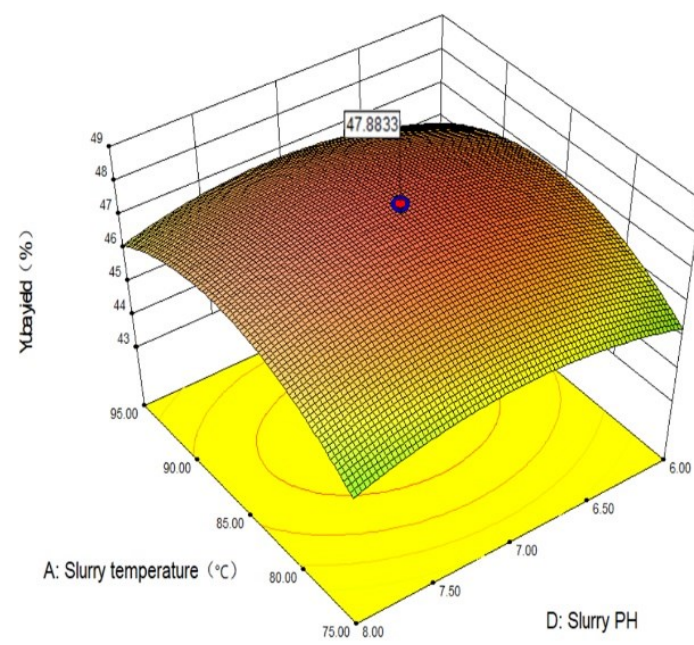

(c) Slurry temperature and slurry $\mathrm{PH}$

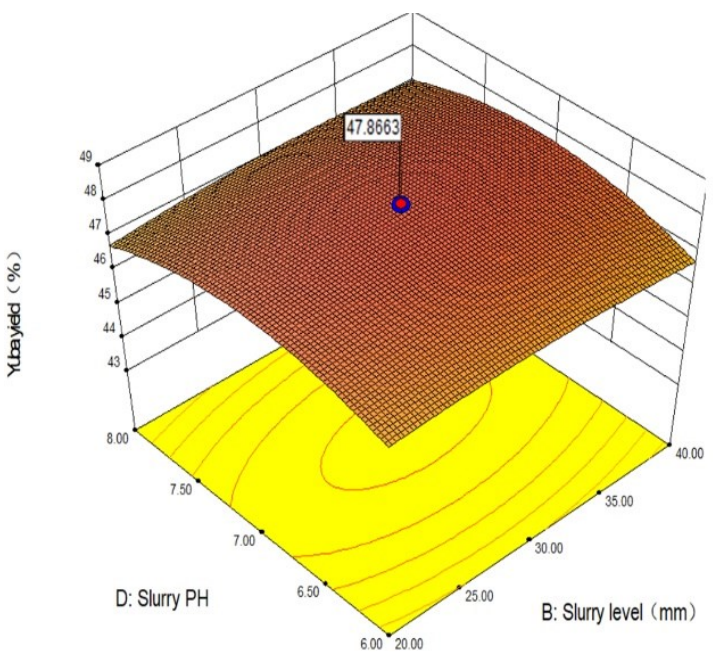

(e) Slurry level and slurry PH

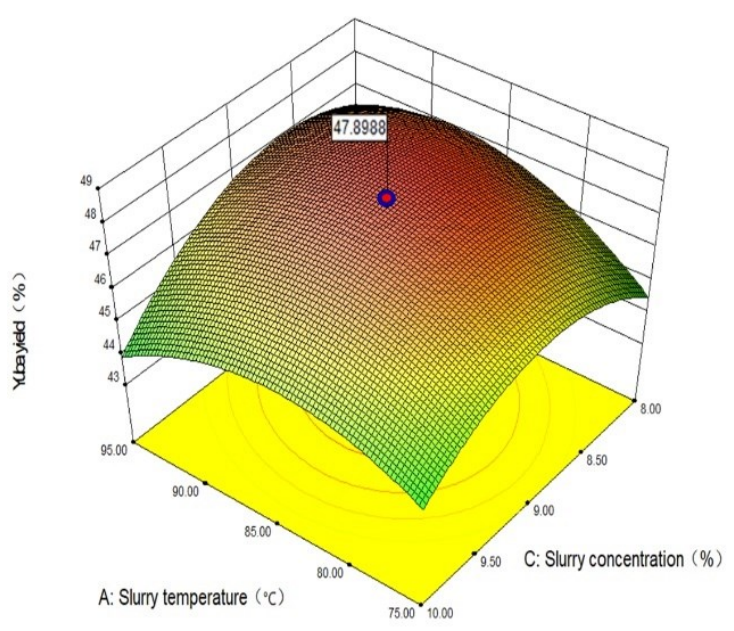

(b) Slurry temperature and slurry concentration

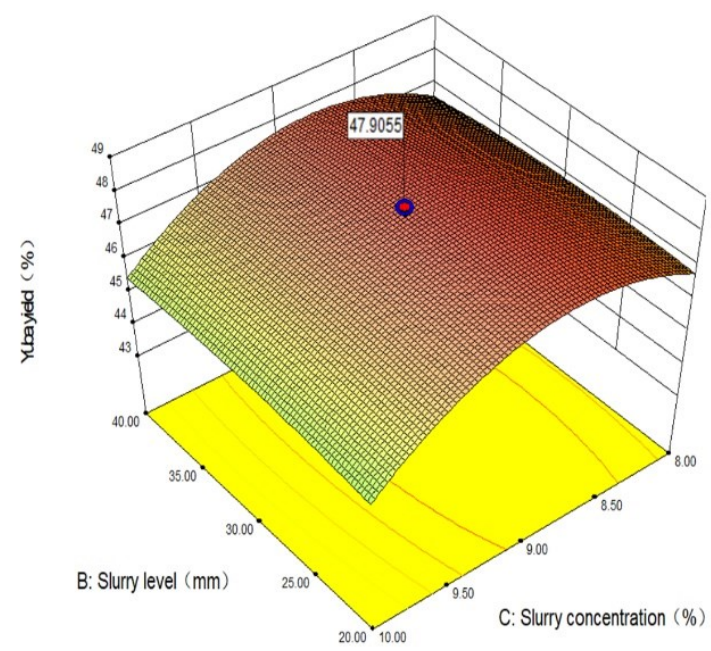

(d) Slurry level and slurry concentration

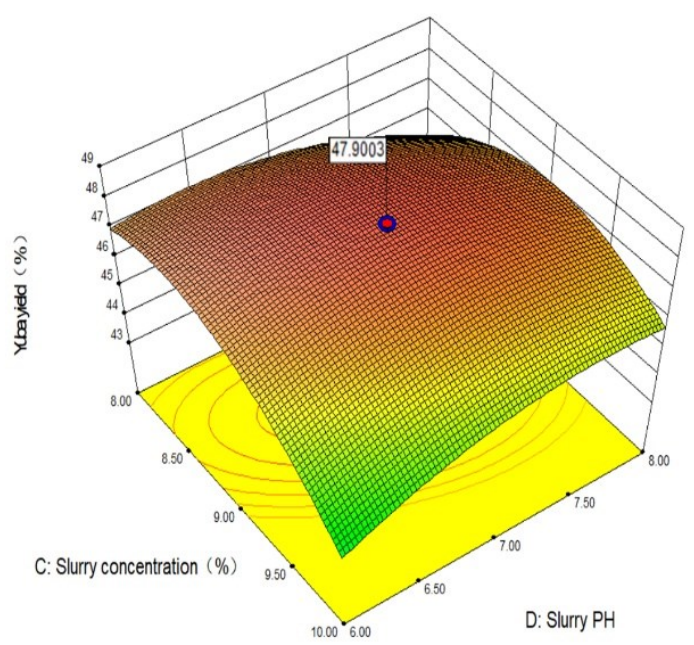

(f) Slurry concentration and slurry $\mathrm{PH}$

Fig. 16 Response surface diagram of the interaction of various factors.

\subsection{Validation of regression model test results}

To verify the reliability of the response surface optimization conditions, the response value of the largest factor was selected for experimental verification. The results are presented in Table 10. Considering the convenience of actual operation 
and conditions of the production process, the slurry concentration, temperature, $\mathrm{pH}$, and level were set to $8.5 \%, 85^{\circ} \mathrm{C}, 7.0$, and $27 \mathrm{~mm}$, respectively, for verification. Yuba was extracted under these conditions. After three sets of parallel experiments, the average yield of yuba was $47.87 \%$, and the error relative to the predicted value was $0.063 \%$. This result indicates that the experimental design and mathematical model are reliable and reproducible and can provide an excellent estimation of the actual application value. The sample for the parallel test verification is presented in Fig. 17.

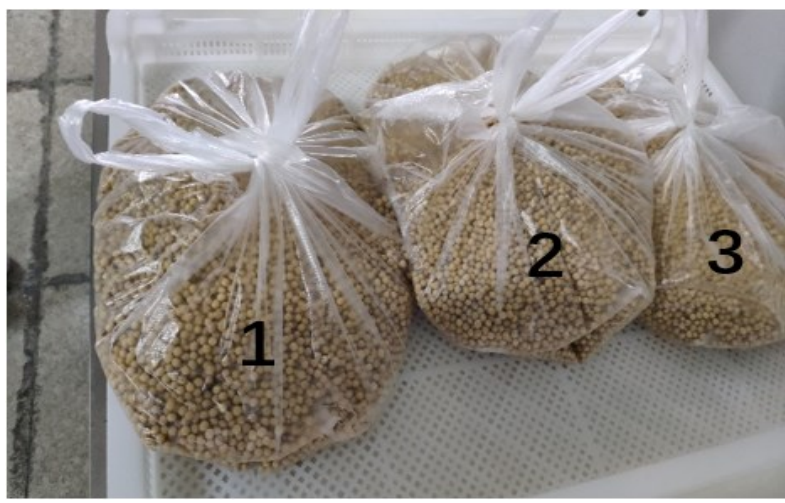

(a) Parallel test dry soybean sample diagram

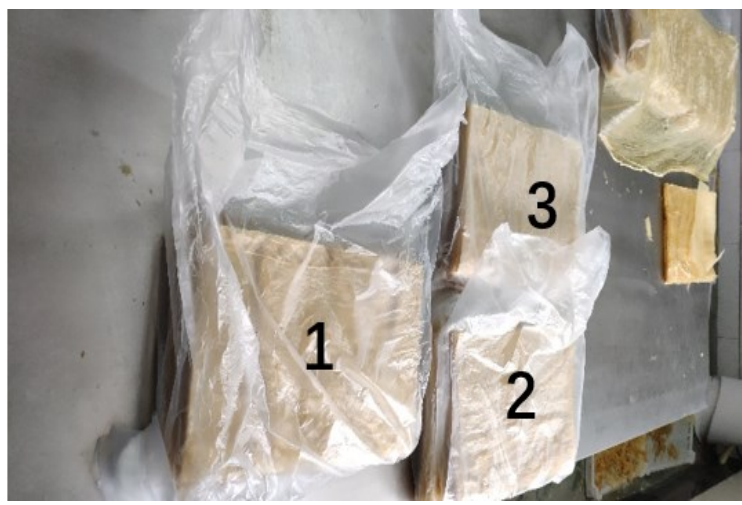

(b) Parallel test dried yuba sample diagram

Fig. 17 Parallel test verification sample.

Table 10 Test verification results.

\begin{tabular}{|c|c|c|c|c|c|}
\hline \multicolumn{3}{|c|}{ Number of trials } & \multirow{2}{*}{ Average value } & \multirow{2}{*}{ Predictive value } & \multirow{2}{*}{ Relative error } \\
\hline First group & Second Group & Third group & & & \\
\hline $47.86 \%$ & $47.89 \%$ & $47.87 \%$ & $47.87 \%$ & $47.90 \%$ & $0.063 \%$ \\
\hline
\end{tabular}

\section{Conclusions}

(1) This study designed a multifactor control system, including an STC12C5A60S2 single-chip microcomputer system module, a power supply module, a sensor measurement module, and a multifactor control module; the study subsequently realized remote data acquisition, processing, and processing on the LabVIEW interface of a host computer.

(2) Comparative analysis results reveal that the measured temperature was within $0.2{ }^{\circ} \mathrm{C}$ of the actual value, the liquid level was within $1 \mathrm{~mm}$ of the actual value, the measured concentration was within $0.1 \%$ of the actual value, and the measured PH was within 0.05 of the actual value. Therefore, the system error does not affect the continuous film formation of yuba, which satisfies design requirements.

(3) An orthogonal test model was established to fit the regression equation. Variance analysis results indicate that the factors could be ordered as follows with respect to their influence on the yield of yuba: slurry concentration $>$ slurry temperature > slurry PH > slurry level. Finally, response surface analysis and a regression model test were performed to obtain optimized yuba production conditions. The analysis results revealed that the optimal production conditions involved a slurry concentration, slurry temperature, slurry $\mathrm{pH}$, and slurry level of $8.50 \%, 85.0^{\circ} \mathrm{C}, 7.0,27.5 \mathrm{~mm}$, respectively, which were associated with a yuba yield of $47.91 \%$.

\section{Acknowledgements}

This work was supported by the National Key Research and Development Program of China (No.2017YFD0700104) and the Natural Science Youth Foundation of Anhui Agricultural University (No.2020zd21).

\section{References}

Anchana., Duangmal, K., and Mahawanich, T., Mechanical, Optical, and Barrier Properties of Soy Protein Film As Affected by 
Phenolic Acid Addition, Journal of Agricultural \& Food Chemistry, Vol.63, No. 43 (2015), pp. 21-36.

Chen, Y., and Ono, T. The mechanisms for Yuba formation and its stable lipid, Journal of Agricultural \& Food Chemistry, Vol. 58, No.10 (2010), pp. 85-99.

Dunn, O.J., and Clark, V.A., Applied statistics: analysis of variance anf regression, Technometrics, Vol. 46, No.4 (2015), pp. 491-492.

Guo., and Yang., Design and Experiment of Digital Display Soymilk Total Solid Content Detector, Journal of Agricultural Machinery, Vol. 47, No.10 (2016), pp. 287-292.

Huang, J., and Bai, Z., Design of a New PH Meter, Journal of Physics Conference Series, Vol.1649 (2020), pp. 12-27.

Hercog, D., Gergič, B., A flexible microcontroller-based data acquisition device, Sensors(Basel, Switzerland), Vol.16, No.6 (2014), pp. 9755-9775.

Husain, A.R., Hadad, Y., and Zainal, M.N., Development of Low-Cost Microcontroller-Based Interface for Data Acquisition and Control of Microbioreactor Operation, Lab Autom, Vol. 21, No. 5 (2016), pp. 660-670.

Jiang, J.H., and Xiao, Z.G., A Study on Liquid Level Measurement and Control System Based on Single Chip Microcomputer, Applied Mechanics \& Materials, Vol. 3744 (2015), pp. 369-372.

Kim, N., Seo, E., and Kim, Y., Physical, Mechanical, and water barrier properties of yuba films incorporated with various types of additives, Journal of the Science of Food \& Agriculture, Vol. 99, No. 6 (2019), pp. 08-17.

Kowalczyk, D., and Baraniak, B., Effects of plasticizers, $\mathrm{pH}$, and heating of film-forming solution on the properties of pea protein isolate films, Journal of Food Engineering, Vol. 105, No.2 (2011), pp. 295-305.

Li, Y., Performance Analysis of Three-Phase Full-Controlled Bridge Rectifier Circuit, Advanced Materials Research, Vol.722, No.1 (2013), pp. 49-53.

Mervyn, G., Marasinghe, and William, J., Kennedy. Analysis of Variance Models, Technometrics, Vol.43, No. 2(2018), pp. 233-234.

Peerkhan, N., and Nair, S., Optimization of wheat dextrin yogurt formulation using response surface methodology, Journal of Food Science \& Technology-Mysore, Vol.4 (2020), pp. 197-200.

Su., Huang., and Yuan., Structure and properties of carboxymethyl cellulose and soy protein isolate blend edible films crosslinked by Maillard reactions, Carbohydrate Polymers, Vol. 79, No. 1 (2009), pp. 145-153.

Siran., and Lee., Chemical composition, water vapor permeability, and mechanical properties of yuba film influenced by soymilk depth and concentration, Journal of the Science of Food \& Agriculture, Vol. 98, No. 5 (2018), pp. 1751-1756.

Tylavsky, D.J., and Trutt, F.C., Complete Analysis of the Operating Modes of the Resistance--Inductance-Fed Bridge Rectifier, IEEE Transactions on Industrial Electronics, Vol. 29, No. 4 (2007), pp. 287-294.

Wang, Y., and Zheng, Z., The Key Technology Research of GPS Positioning System Based on Single Chip Microcomputer, Key Engineering Materials, Vol. 1(2010), pp. 286-291.

Xu, X.H., and He, M.Z., Experimental design and Design-Expert, SPSS application, Science Press, Vol.5 (2010), pp. 13-15 (in Chinese).

Yongjie, L., Maomao, Z., Zhiyong H., and et al., Research Progress of Yuba Processing Technology and Quality Influencing Factors, Food Science, Vol. 34, No. 23 (2013), pp. 333-337 (in Chinese).

Yu, Y.J., Application analysis of single-chip microcomputer technology in IOT electronic intelligent products, Microprocessors \& Microsystems, Vol. 1 (2020), pp. 1034-1068.

Zhi, H., Ishitani, T., and Zai L., The effect of different soybean milk concentrations and slurry depth on yuba production, Journal of Agricultural Engineering, Vol. 21, No.11(2005), pp. 187-189 (in Chinese). 